See Article page 41.

\section{Commentary: Take your time!}

\author{
Antonio Miceli, MD, PhD
}

Permanent pacemaker implantation (PPI) is a frequent complication after transcatheter aortic valve replacement (TAVR). Plenty of risk factors may affect PPI, include right bundle branch block (BBB), depth of prosthetic aortic valve implantation, oversizing or repositioning, valvuloplasty, and excessive calcium on a small aortic annulus have been associated with a higher rate of PPI after TAVR. ${ }^{1,2}$ The timing of pacemaker implantation is often variable and depends mainly on the electrophysiology cardiologist's policy. However, a period of clinical observation of up to 7 days is recommended to assess whether the rhythm disturbance is transient and will resolve. ${ }^{3}$ A multicenter retrospective analysis of 859 patients requiring PPI after cardiac surgery found that found that $30 \%$ were pacemaker-independent at 6 months. ${ }^{4}$ Interestingly, pacemaker dependency was associated with an increased risk of long-term mortality. This information raises some doubts regarding the correct timing for PPI.

In this issue of JTCVS Open, Ravaux and colleagues ${ }^{5}$ provide evidence that a number of patients receiving a PPI for atrioventricular (AV) block have their preoperative rhythm restored after several months. ${ }^{5}$ According to this meta-analysis, mean pacing dependency at 1 year was $47.5 \%$ (range, $7 \%-89 \%$ ). As expected, patients with preoperative right $\mathrm{BBB}$ and those receiving self-expandable prostheses had a 2-fold increased risk of requiring PPI. The article raises 2 considerations. First, a period of "wait and see" is recommended to avoid an ineffective pacemaker implantation. Most studies have reported a median time of 3 days for PPI, whereas a minimum period of 7 days should

From the Minimally Invasive Cardiac Department, Istituto Clinico Sant'Ambrogio, Milan, Italy.

Disclosures: The author reported no conflicts of interest.

The Journal policy requires editors and reviewers to disclose conflicts of interest and to decline handling or reviewing manuscripts for which they may have a conflict of interest. The editors and reviewers of this article have no conflicts of interest.

Received for publication Feb 25, 2021; accepted for publication Feb 26, 2021; available ahead of print March 26, 2021.

Address for reprints: Antonio Miceli, MD, PhD, Minimally Invasive Cardiac Department, Istituto Clinico Sant'Ambrogio, via LG Faravelli 16, Milano, Italy (E-mail: antoniomiceli79@alice.it).

JTCVS Open 2021;6:56-7

2666-2736

Copyright $@ 2021$ The Authors. Published by Elsevier Inc. on behalf of The American Association for Thoracic Surgery. This is an open access article under the CC BY-NCND license (http://creativecommons.org/licenses/by-nc-nd/4.0/).

https://doi.org/10.1016/j.xjon.2021.02.009

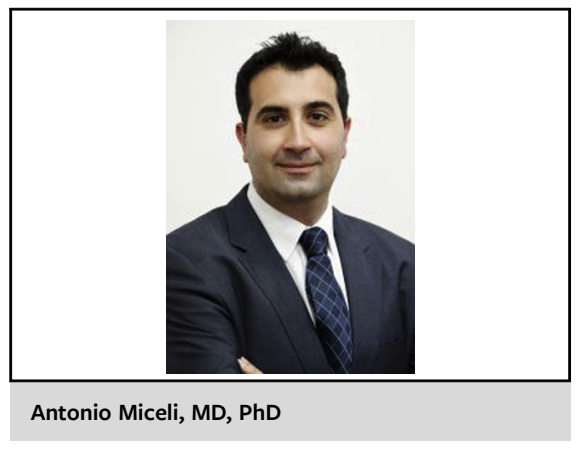

CENTRAL MESSAGE

A "wait and see" policy of at least

of 1 week may reduce the inci-

dence of permanent pacemaker

implantation.

be considered in cases of advanced AV block. This policy might reduce health costs, patient discomfort, and most of all improve survival, as pacemaker implantation has been considered a potential risk factor for poor survival at follow-up. ${ }^{4}$

Second, balloon-expandable valves should be considered over self-expandable valves in those patients with such risk factors as right BBB, small annuli, and calcified aortic valves.

This meta-analysis is limited by the small number of studies, and among the 23 studies identified, 15 reported 1 -year dependency and only 6 reported the influence of baseline right $\mathrm{BBB}$, atrial fibrillation, and type of valve at 1-year follow-up. The low number of studies evaluating outcomes limits the quality of this meta-analysis. Moreover, $18 \%$ of patients requiring PPI underwent PPI for bradycardia, sick sinus syndrome, or other reasons than advanced AV block. Consequently, we do not know the actual incidence of pacemaker dependency in patients with AV block. Finally, no information is reported regarding patients with new onset of left BBB who required PPI at follow-up. The presence of left BBB has been associated with a 2fold increased risk of PPI at 1 year. $^{6}$

In conclusion, even though PPI is a frequent complication after TAVR, one-half of patients do not exhibit pacemaker dependency at a 1-year follow-up. This implies the need for a "wait and see" policy of at least of 1 week to avoid inappropriate PPI.

\section{References}

1. Auffret V, Puri R, Urena M, Chamandi C, Rodriguez-Gabella T, Philippon F, et al. Conduction disturbances after transcatheter aortic valve replacement: current status and future perspectives. Circulation. 2017;136:1049-69. 
2. Al-Azzam F, Greason KL, Krittanawong C, Williamson EE, McLeod CJ, King KS, et al. The influence of native aortic valve calcium and transcatheter valve oversize on the need for pacemaker implantation after transcatheter aortic valve insertion. J Thorac Cardiovasc Surg. 2017;153: 1056-62.e1.

3. Epstein AE, DiMarco JP, Ellenbogen KA, Estes NAM III, Freedman RA, Gettes LS, et al. 2012 ACCF/AHA/HRS focused update incorporated into the ACCF/AHA/HRS 2008 guidelines for device-based therapy of cardiac rhythm abnormalities: a report of the American College of Cardiology Foundation/American Heart Association task force on practice guidelines and the Heart Rhythm Society. J Am Coll Cardiol. 2013;61:e6-75.
4. Lorusso R, Ravaux JM, Barili F, Bidar E, Vernooy K, Di Mauro M, et al. Relation of prolonged pacemaker dependency after cardiac surgery to mortality. Am J Cardiol. 2021;138:66-71.

5. Ravaux JM, Di Mauro M, Vernooy K, Van't Hof AW, Veenstra L, Kats S, et al. One-year pacing dependency after pacemaker implantation in patients undergoing transcatheter aortic valve implantation: systematic review and meta-analysis. $J$ Thorac Cardiovasc Surg Open. 2021;6:41-55.e15.

6. Reguerio A, Altisent OAJ, Del Trigo M, Campelo-Parada F, Puri R, Urena M, et al Impact of new-onset left bundle branch block and periprocedural permanent pacemaker implantation on clinical outcomes in patients undergoing transcatheter aortic valve replacement: a systematic review and meta-analysis. Circ Cardiovasc Interv. 2016;9:e003635. 